\title{
Diabetes mellitus as a Potential Risk Factor for Renal Disease among Nepalese:
}

\section{A Hospital Based Case Control Study}

\author{
Mittal A ${ }^{1}$, Sathian B 2 , Kumar A ${ }^{3}$, Chandrasekharan N ${ }^{4}$, Sunka $A^{5}$
}

${ }^{1}$ Assistant Professor, Department of Biochemistry, Manipal College of Medical Sciences, Pokhara, Nepal

${ }^{2}$ Assistant Professor, Department of Community Medicine, Manipal College of Medical Sciences, Pokhara,

Nepal

${ }^{3}$ Assistant Professor, Department of Biochemistry, College of Medicine \& JNM Hospital, West Bengal, India

${ }^{4}$ Assistant Professor, Department of Orthopaedics, Manipal College of Medical Sciences, Pokhara, Nepal

${ }^{5}$ Final Year MBBS Student, Manipal College of Medical Sciences, Pokhara, Nepal

\section{Original Article}

\section{Corresponding Author:}

Dr. Ankush Mittal, Assistant Professor, Department of Biochemistry Manipal College of Medical Sciences, Pokhara,

Nepal.

Email: drmittala@gmail.com

\section{Abstract}

\section{Background}

Diabetes mellitus is a well recognized public health concern and projections of its future effect are alarming. It is one of the leading causes of end stage renal disease in both developed and emerging nations. The objective of the present study was to assess the progressive deterioration of renal function in Diabetes mellitus among Nepalese.

\section{Materials and Methods}

It was a hospital based case control study carried out in the Department of Biochemistry of Manipal Teaching Hospital, Pokhara, Nepal between $1^{\text {st }}$ January 2010 and $31^{\text {st }}$ August 2010. The variables collected were age, gender, random blood glucose, serum urea and creatinine levels of the patients.

\section{Results}

Out of 440 patients, there was a slight predominance of males $(54.1 \%)$ as compared to females $(45.8 \%)$. Patients in between 41-100 years were 2.8 times more at risk of developing kidney disease as compared to age group (0-40 years)(Odds Ratio $=2.8, p=0.0001)$. Diabetic patients were twice at risk of developing kidney disease than non diabetics (Odds Ratio=1.97, $p=0.001$ ). There was a significant increase in mean values of serum creatinine $(\mathrm{Cl} 4.3$ to 4.8$)$ and urea (Cl 118.55 to 153.50) in kidney disease patients with Diabetes mellitus. In non diabetic kidney disease patients, mean values of serum creatinine $(\mathrm{Cl} 3.29$ to 3.70) and urea (Cl 98.88 to 116.92 ) were also moderately raised as compared to controls.

\section{Conclusion}

Diabetic renal lesions are not only preventable but also reversible. In summary, glycemic control significantly influences the rate of progression from microalbuminuria to proteinuria and from overt nephropathy to end stage renal disease. The best modality of treatment includes strict control over blood glucose levels and its evaluation at frequent intervals.

\section{Key Words}

Diabetic Mellitus, Kidney Disease, Case Control Study, Nepal

\section{Background}

Diabetic mellitus is a metabolic disorder of multiple aetiology, characterized by chronic hyperglycemia. The increase in blood glucose concentration is mainly due to insulin deficiency or ineffectiveness in its action, which in turn damages major systems of human body particularly blood vessels and nerves ${ }^{1}$. According to WHO, diabetes affects more than 170 million people worldwide, and this number will rise to 370 million by $2030^{2}$. About one third of those affected will eventually have progressive deterioration of renal function ${ }^{3}$. Factors such as sedentary 
lifestyle, dietary modifications, genetic mutations, ethnicity, hypertension and obesity have led to a dramatic increase in the incidence of Diabetes mellitus, especially in the 21st century ${ }^{4}$. Diabetes is now the major cause of end stage kidney failure throughout the world in both developed and emerging nations. Chronic kidney disease usually is silent and undetected until advanced stages with adverse outcomes of kidney failure, cardiovascular disease and premature death. A strong association is well recognized between the presence of diabetes, hypertension, chronic kidney disease and cardiovascular diseases ${ }^{5}$. The number of patients dependent upon renal replacement therapy was approximately 400000 in year 2000 and by 2030 number is expected to increase upto 2 million in USA. More than 600000 patients require renal replacement therapy, costing around $\$ 28$ billion by the year 2010 in USA $^{6}$. The rise in prevalence, progression and complications of chronic kidney disease is probably attributable to a progressively aging population, duration of diabetes and presence of hypertension ${ }^{7}$. The Nepal Diabetes Association reported that diabetes affects approximately $15 \%$ of people $\geq 20$ years and $19 \%$ of people $\geq 40$ years of age in urban areas ${ }^{8}$. The increasing number of treated end stage renal disease cases was partly explained by the increase in diabetes prevalence in Nepal. According to WHO, diabetes affects more than 436,000 people in Nepal, and this number will rise to $1,328,000$ by $2030^{2}$. The percentage of diabetic patients has increased from $19.04 \%$ in 2002 to $25.9 \%$ in 2009 in Nepal $^{9}$. Diabetic nephropathy is one of the most common long term sequelae of Diabetes mellitus and it is the single largest cause of end stage renal disease worldwide and accounting for 20 to $40 \%$ of new cases ${ }^{10}$. Diabetes mellitus is usually associated with dyslipidemia, hypertension and visceral adiposity, which collectively increases the comorbid risk of developing chronic kidney disease ${ }^{5}$. The current study was designed with an objective to assess the progressive deterioration of renal function in Diabetes mellitus among Nepalese in Pokhara valley.

\section{Materials and Methods}

It was a hospital based case control study carried out in the Department of Biochemistry of Manipal Teaching Hospital, Pokhara, Nepal between $1^{\text {st }}$ January 2010 and $31^{\text {st }}$ August 2010. Approval for the study was obtained from the institutional research ethical committee.

Samples collected from 440 cases were analyzed in this study. The variables collected were age, gender, random blood glucose, serum urea and creatinine levels of the patients. Patients presenting to the Medicine OPD with chief complaints of oliguria, past history of Diabetes mellitus for 5 years, referred for dialysis, were taken as cases in our current study. The patients excluded were smokers, hypertensives, hyperlipidemics and pregnant women. Investigations of serum creatinine, urea and random blood sugar were sent for all of them. Subjects with normal renal function tests and random blood glucose were selected as controls.
Estimation of blood glucose was done by glucose oxidase and peroxidase method ${ }^{11}$. Similarly, serum urea was estimated by enzymatic method ${ }^{12}$ while creatinine was estimated by alkaline Jaffe's Picrate method ${ }^{13}$. All these laboratory parameters were analyzed using Human reagent kits and with the help of semi autoanalyser (Humalyser 3500 , Germany). The WHO criteria for establishing Diabetes mellitus (random blood glucose $\geq 200 \mathrm{mg} / \mathrm{dl}$ ) was followed to categorize the people with Diabetes mellitus. The presence of kidney disease was established solely on the basis of abnormal serum urea and creatinine values.

Descriptive statistics and testing of hypothesis were used for the analysis. The data collected was analyzed using Excel 2003, R 2.8.0 Statistical Package for the Social Sciences (SPSS) for Windows Version 16.0 (SPSS Inc; Chicago, IL, USA) and EPI Info 3.5.1 Windows Version. Mean and SD are reported for variables. Pearson correlation was used for assessing the degree of relationship. The Chi-square test was used to examine the association between different variables. Z-test was used to compare the significance difference between two variables. A $p$-value of $<0.05$ (twotailed) was used to establish statistical significance. For $5 \%$ significance level, power $80 \%$, case to control allocation 1:1, expected frequency of exposure in the not-ill group (controls) is $30 \%$, odds ratio 2 , and expected frequency of exposure in ill group (cases) is $46.15 \%$. Sample size required was 153 cases and 153 controls with a total of 306 subjects $^{14}$.

\section{Results}

Of the 440 patients, there was a slight predominance of males (54.1\%) as compared to females (45.8\%). $28.9 \%$ were diagnosed to have Diabetes mellitus and $43.2 \%$ had kidney disease.

Table 1: Relationship between kidney disease and other variables

\begin{tabular}{|ll|l|l|c|}
\hline \multirow{2}{*}{ Variables } & \multicolumn{2}{c|}{ Kidney disease } & \multirow{2}{*}{ p-Value } \\
\cline { 3 - 4 } & & \multicolumn{1}{c|}{ YES } & \multicolumn{1}{c|}{ NO } & \\
\hline Gender & Male & 111 & 127 & 0.112 \\
\cline { 2 - 4 } Age group & Female & 79 & 123 & \\
\cline { 2 - 4 } & $41-100$ & 164 & 173 & $0.0001^{* *}$ \\
\hline Diabetes & $0-40$ & 26 & 77 & \\
mellitus & YES & 70 & 57 & $0.001^{* *}$ \\
\hline
\end{tabular}

** Statistically significant ( $\mathrm{p}$ value $<0.05$ )

Table 1 depicts that there was quantitatively small gender differences in kidney disease patients but they were but not significant statistically $(p=0.112)$. Patients in between 41100 years were 2.8 times more at risk of developing kidney disease as compared to age group (0-40 years) (Odds Ratio=2.8, $p=0.0001$ ). Diabetes mellitus patients were twice at risk of kidney disease as compared to non diabetics (Odds Ratio=1.97, $p=0.001$ ). 
Table 2: Comparison of biochemical parameters in cases (kidney disease)

\begin{tabular}{|l|l|l|l|}
\multirow{2}{*}{ Variables } & \multicolumn{2}{|c|}{ Diabetes mellitus } & \multirow{2}{*}{ p-Value } \\
\cline { 2 - 3 } & \multicolumn{1}{|c|}{ Yes (70) } & \multicolumn{1}{|c|}{ No (120) } & \\
\hline Age & $64.9 \pm 12.9$ & $58.4 \pm 21.07$ & $0.022^{* *}$ \\
Creatinine & $4.6 \pm 1.18$ & $3.5 \pm 1.14$ & $0.013^{* *}$ \\
\hline Urea & $136.03 \pm 74.6$ & $107.9 \pm 50.4$ & $0.002^{* *}$ \\
\hline
\end{tabular}

$* *$ Statistically significant ( $\mathrm{p}$ value $<0.05$ )

Table 2 shows the comparison of age, serum creatinine and urea in kidney disease patients (cases) with and without Diabetes mellitus. There was a significant increase in mean values of serum creatinine $(\mathrm{Cl} 4.3$ to 4.8$)$ and urea $(\mathrm{Cl}$ 118.55 to 153.50 ) in kidney disease patients with Diabetes mellitus. In non diabetic kidney disease patients, mean values of serum creatinine $(\mathrm{Cl} 3.29$ to 3.70$)$ and urea $(\mathrm{Cl}$ 98.88 to 116.92 ) were also moderately raised as compared to controls.

Table 3: Comparison of biochemical parameters in controls (non kidney disease)

\begin{tabular}{|l|c|c|c|}
\multirow{2}{*}{ Variables } & \multicolumn{2}{|c|}{ Diabetes mellitus } & \multirow{2}{*}{ p Value } \\
\cline { 2 - 3 } & Yes (57) & No (193) & \\
\hline Age & $61.2 \pm 12.8$ & $47.75 \pm 19.8$ & $0.001^{* *}$ \\
Creatinine & $1.13 \pm 0.20$ & $1.03 \pm 0.07$ & $0.002^{* *}$ \\
Urea & $35.49 \pm 7.6$ & $32.36 \pm 6.5$ & $0.032^{* *}$ \\
\hline
\end{tabular}

$* *$ Statistically significant ( $\mathrm{p}$ value $<0.05$ )

Table 3 displays that mean values obtained for serum creatinine $(\mathrm{Cl} 1.08$ to 1.17$)$ in diabetic subjects with no kidney disease were mildly increased when compared to normal patients ( $\mathrm{Cl} 1.02$ to 1.04).

Figure 1: Correlation between serum urea and creatinine in kidney disease patients

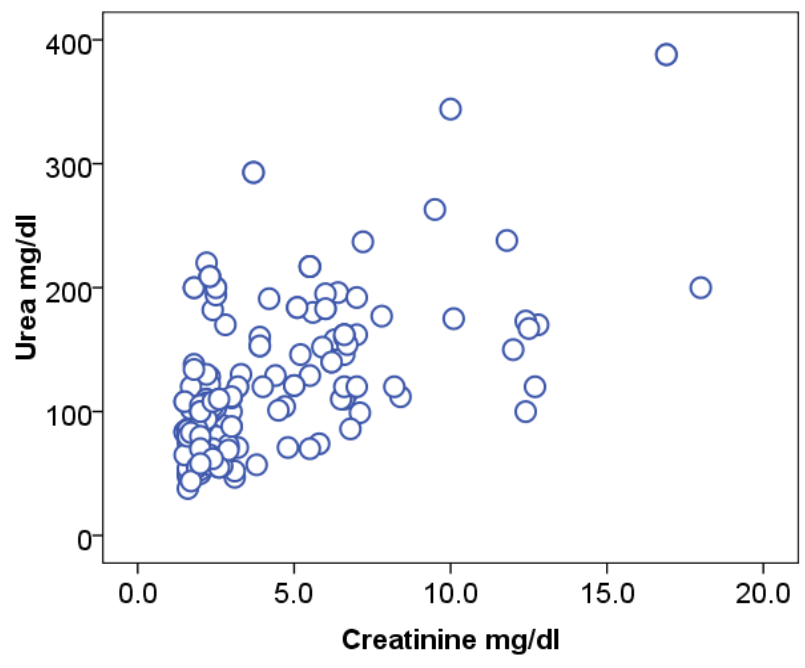

Figure 1 shows that serum urea level increases proportional to the increase in serum creatinine $(r=0.601, p=0.001)$.

\section{Discussion}

Diabetes mellitus is a slow, progressive disease characterized by hyperglycemia. Over time, high blood sugar levels damage millions of nephrons - tiny filtering units within each kidney. As a result, kidneys are unable to maintain the fluid and electrolyte homeostasis. Creatinine is filtered by the glomerulus; therefore, serum creatinine level is used as an indirect measure of glomerular filtration. As glomerular filtration rate (GFR) diminishes, there is a rise in plasma concentrations of serum creatinine and urea. Furthermore, this rise indicates progression of kidney disease and estimation of serum creatinine has greater $\mathrm{pr}$ ognostic ability compared with urea for predicting the adverse outcomes. Our present study showed significant increase in mean values of serum creatinine and urea i.e 4.6 \pm SD1.18 mg/dl and $136.03 \pm$ SD $74.6 \mathrm{mg} / \mathrm{dl}$ respectively in kidney disease patients with Diabetes mellitus. In non diabetic kidney disease patients, the mean values of serum creatinine $(3.5 \pm$ SD1.14 mg/dl) and urea (107.9 \pm SD 50.4 $\mathrm{mg} / \mathrm{dl}$ ) were also moderately raised as compared to controls. In a similar study conducted by Shiv Kapoor et al on chronic kidney disease, mean values of serum creatinine in patients suffering from chronic kidney disease was $3.5 \pm$ SD $2.6 \mathrm{mg} / \mathrm{dl}$, which was almost equivalent to our non diabetic kidney disease patients ${ }^{15}$. The previous studies also emphasized that serum creatinine levels (2.24 \pm SD0.34 $\mathrm{mg} / \mathrm{dl}$ ) was increased significantly in patients with diabetic nephropathy when compared to controls ${ }^{16}$. Therefore, raised serum urea and creatinine levels in diabetics clearly indicate that prolonged hyperglycaemia causes irreversible damage to nephrons of kidney. Raised serum creatinine and reduced GFR has become firmly entrenched as fairly reliable indicators of kidney dysfunction. Another important finding of our present study was that the mean values obtained for serum creatinine $(1.13 \pm$ SD $0.20 \mathrm{mg} / \mathrm{dl})$ in diabetic subjects with no kidney disease were mildly increased when compared to normal patients $(1.03 \pm \mathrm{SD} 0.07 \mathrm{mg} / \mathrm{dl})$. The above results corresponded with findings of Puepet et al $(2003)^{17}$. In similar studies done previously, no significant elevation in mean value of serum creatinine was observed in diabetic patients without nephropathy $(1.28 \pm S D$ $0.43 \mathrm{mg} / \mathrm{dl})$ when compared to controls (1.22 $\pm \mathrm{SD}$ $0.55 \mathrm{mg} / \mathrm{dl})^{16}$. In our current study, patients in between 41 100 years were 2.8 times more at risk of developing kidney disease as compared to age group (0-40 years). The prevalence of chronic kidney disease is indeed rising consistently with ageing of the general population ${ }^{18}$. Hypertension is a known risk factor for kidney disease and people with diabetes are prone to hypertension. Genetic predisposition to hypertension is associated with an increased risk of diabetic nephropathy. Kidneys affected by diabetic nephropathy no longer work efficiently. Hyperglycemia is a precondition for developing two major early glomerular lesions, glomerular basement membrane (GBM) thickening and mesangial expansion, which are not present at the diagnosis of Diabetes but are found 2 to 5 yrs after onset of hyperglycemia ${ }^{19}$. In chronic hyper-glycaemia, 
there is non enzymatic glycation/oxidation of aminoacids, lipids and lipoproteins. The formation of advanced glycation end-products (AGEs) has long been recognized as a fundamental mechanism of cellular injury in diabetes. The accumulation of AGEs accelerates atherogenesis, increased vascular permeability, basement membrane thickening, increased extracellular matrix and mesangial fibrosis. This process leads the way to eventual glomerulosclerosis and renal failure ${ }^{20}$. Only 97 hemodialysis machines are available for renal replacement therapy in Nepal ${ }^{21}$. Therefore, early therapeutic interventions in patients with chronic kidney disease or diabetes can delay onset of complications, reduce mortality and overcome the cost of renal replacement therapy in Nepal.

\section{Conclusion}

The current study reveals a compelling association between diabetic mellitus and chronic kidney disease. Diabetic renal lesions are not only preventable but also reversible. In summary, glycemic control significantly influences the rate of progression from microalbuminuria to proteinuria and from overt nephropathy to end stage renal disease. The best modality of treatment includes strict control over blood glucose levels and its evaluation at frequent intervals. Simple, cheap and reliable biochemical parameters should be used in countries having low socioeconomic status with less sophisticated health systems like Nepal for screening such as estimation of serum urea, creatinine, blood glucose levels and measuring of blood pressure. Therefore, it is time for health care programmes to facilitate early detection and treatment of people suffering from Diabetes mellitus and chronic kidney disease.

\section{Conflict of Interests}

The authors do not have any conflict of interests arising from the study.

\section{Acknowledgements}

Dr. B M Nagpal, CEO Manipal Education and Medical group \& Dean, Manipal College of Medical Sciences, P O Box No 155, Deep Heights Pokhara (Nepal) for permitting the authors to use the hospital documents during the study.

\section{References}

1. Mehta RS, Karki P, Sharma SK. Risk factors, associated health problems, reasons for admission and knowledge profile of diabetes patients admitted in BPKIHS. Kathmandu Univ Med J 2006;4(1),11-3.

2. Wild SH, Roglic G, Sicree R, Green A, King H: Global Burden of Diabetes mellitus in the Year 2000. [online] 2004 [cited 2010 October 15]. Available from: http://www3.who. int/whosis/menu.cfm?path=evidence,burden,burden - gbd 2000 docs\&language $=$ english

3. Remuzzi G, Schieppati A, Ruggenenti P. Clinical practice. Nephropathy in patients with type 2 diabetes. N Engl J Med 2002;346(15):1145-51.
4. Zimmet P, Alberti KG, Shaw J. Global and societal implications of the diabetes epidemic. Nature 2001; 414 (6865):782-7.

5. Whaley-Connell A, Sowers JR, McCullough PA, Roberts T, McFarlane SI, Chen SC et al. Diabetes mellitus and CKD awareness: the Kidney Early Evaluation Program (KEEP) and National Health and Nutrition Examination Survey (NHANES). Am J Kidney Dis 2009;53(4):S11-21.

6. Xue JL, Ma LZ, Louis TA, Collins AJ. Forecast of the number of patients with the end stage renal disease in the United States. J Am Soc Nephrol 2001; 12: 2753-8.

7. Norris K, Nissenson AR. Race, gender, and socioeconomic disparities in CKD in the United States. J Am Soc Nephrol 2008;19(7): 1261-70.

8. Bhattarai MD, Singh DL. Learning the lessons - preventing type 2 diabetes in Nepal. Diabetes Voice 2007;52( 2): 9-10.

9. Dulal RK, Karki S. Disease management programme for Diabetes mellitus in Nepal. J Nepal Med Assoc 2009; 48(176):281-6.

10. Agha A, Amer W, Anwar E, Bashir K. Reduction of microalbuminuria by using losartan in normotensive patients with type 2 Diabetes mellitus: A randomized controlled trial. Saudi J Kidney Dis Transpl 2009;20(3):42935.

11. Trinder P. Determination of glucose in blood using glucose oxidase with an alternative oxygen acceptor. Ann Clin Biochem 1969; 6:24-7.

12. Fawcett JK, Scott JE. A rapid and precise method for the determination of urea. J Clin Pathol 1960;13:156-9.

13. Owen JA, Iggo B, Scandrett FJ, Stewart CP. The determination of creatinine in plasma or serum, and in urine; a critica1examination. Biochem J 1954; 58(3):426-37.

14. Sathian B, Sreedharan J, Baboo N S, Sharan K, Abhilash E $S$, Rajesh E. Relevance of Sample Size Determination in Medical Research. NJE 2010; 1(1): 4-10.

15. Kapoor S, Cohen D, Townsend R. Effects of Chronic Kidney Disease on Pulse Counter Analysis. Indian J Nephrol 2007; 17(3):94.

16. Shahid SM, Mahboob T. Clinical correlation between frequent risk factors of diabetic nephropathy and serum sialic acid. Int J Diabetes \& Metabolism 2006; 14: 138-42.

17. Puepet FH, Agaba El, Chuhwak EK. Some metabolic abnormalities in type 2 diabetic patients in Jos, north central Nigeria. Niger J Med 2003;12(4):193-7.

18. Glassock RJ, Winearls C. An epidemic of chronic kidney disease: fact or fiction?. Nephrol Dial Transplant 2008; 23(4): 1117-21.

19. Fioretto $P$, Bruseghin $M$, Berto I, Gallina P, Manzato E, Mussap M. Renal protection in diabetes: role of glycemic control. J Am Soc Nephrol 2006;17(4):S86-9.

20. Salahudeen AK, Kanji V, Reckelhoff JF, Schmidt AM. Pathogenesis of diabetic nephropathy: a radical approach. Nephrol Dial Transplant 1997; 12(4): 664-8.

21. Hirachan P, Kharel T, Shah DS, Ball J. Renal replacement therapy in Nepal.Hemodial Int 2010 ; s14(4):383-6. 